\title{
Editorial
}

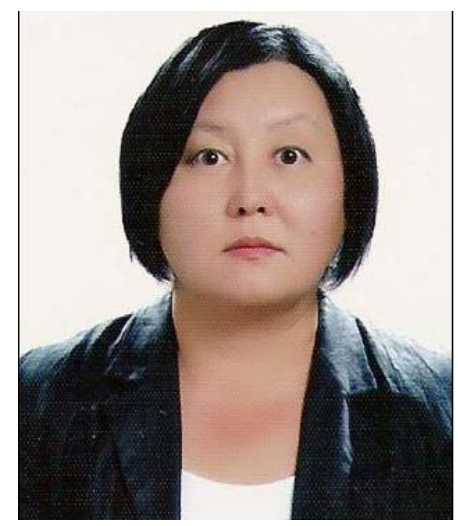

\section{On September 2021 issue, hot trials at ESC congress this year, and updates on pandemics}

In this September 2021 issue of the journal, we present novel original research on value of cardiac biomarkers in prediction of cardiac remodeling after acute myocardial infarction (MI) estimated by magnetic resonance imaging (MRI); contemporary review on vascular approaches to cardiac interventions, focusing on brachial and radial approaches; very interesting case reports - on conduction disturbance and pacemaker implantation after heart transplant, anatomy by advanced imaging of aortic dissection after endovascular repair and cardiac sarcoma case confirmed at autopsy; quiz on electrocardiography of implantable loop recorder (ILR) in evaluation of syncope; and two historical notes on the first female heart surgeon - Nina Starr Braunwald, reflecting different aspects of an outstanding woman and colleague.

The 2021 ESC congress had finished few days ago, as always it was full of new evidence-based knowledge: results of important randomized controlled trials (1) and four guidelines were presented - on acute and chronic heart failure (HF) (2), CRT and cardiac pacing (3), valvular heart disease (4) and cardiovascular disease prevention (5). You may find Editorials on what is new in heart failure (HF) management and cardiac resynchronization therapy (CRT) and pacing, summarized by our Editors in this September issue of the journal, the rest 2 guidelines news will be published later online and in December 2021 issue.

Among trials presented at congress several caught our attention being of multidisciplinary interest (1) .

EMPEROR- pooled trial demonstrated that sodiumglucose luminal co-transporter (SGLT 2) inhibitor empagliflozin (drug used in glucose lowering therapy in type tll diabetes) reduced cardiovascular death or hospitalizations by more than $30 \%$ in patients with $\mathrm{HF}$ and reduced $(<40 \%)$ (HFrEF) or preserved (HFpEF) $(>40 \%)$ ejection fraction. Empagliflozin reduced renal outcomes in HFrEF, but not in HFpEF. Thus this drug confers protection against death and hospitalization in HF patients. These results have not been yet reflected in new HF guideline, as both guideline and study results were presented at the same congress (1).

Interesting studies on high blood pressure (BP) management were presented at congress and may suggest revising target BP levels and diet modification in elderly with more evidence aggregation. STEP study showed that systolic BP reduction $<130 \mathrm{mmHg}$ as compared to $<150 \mathrm{mmHg}$ in elderly population $(60-80$ years old) reduced primary endpoint (stroke, acute coronary syndrome (ACS), decompensated HF, coronary revascularization, atrial fibrillation (AF), and death) by $26 \%$, stroke and ACS by $33 \%$ each, with no difference in renal outcomes but one should be cautious of hypotension.

Address for correspondence: Gulmira Kudaiberdieva, Editor-in-Chief Heart, Vessels and Transplantation, Email: editor@hvt-journal.com

Received: 08.09.2021 Accepted: 09.09.2021

Copyright (02021 Heart, Vessels and Transplantation

doi: $10.24969 /$ hvt.2021.270 
Another study on effect of sault substitution $(25 \% \mathrm{KCl}$ and $75 \% \mathrm{NaCl}$ ) on stroke and death in patients with previous stroke or older than 60 years with poorly controlled BP demonstrated that sault substitution was associated with $14 \%$ reduction in stroke and $12 \%$ reduction in death during 4.74 years follow-up, rate of adverse events due to hyperkalemia was similar in both groups.

In patients with ACS undergoing primary coronary intervention with drug-eluting stenting, there was no benefit of monotherapy with clopidogrel 12 months after 1 month of dual antiplatelet therapy (aspirin plus clopidogrel) for (STOPDAPT 2 ACS trial). SMART-MI trial pursued question whether implantable cardiac monitoring (ICM) will help to detect arrhythmias early and improve prevention of major cardiac and cerebrovascular events in post-AMI patients with moderately reduced EF (36-50\%) and autonomic dysfunction as compared to conventional care. It is known that patients with $\mathrm{EF}<35 \%$ have indication for ICD as primary prevention of sudden cardiac death. It appeared that ICM monitoring helped to detect arrhythmias with higher sensitivity but lead to reduction of cardiac and cardiovascular events to the almost similar level as conventional care (positive predictive accuracy was the same $62 \%$ and $61 \%$ ). More screening studies should be done in this category of patients with additional risk stratifies.

Another monitoring study - LOOP study from Danish registry - in elderly $<70$ years and one stroke risk factor (hypertension, diabetes, HF or previous stroke) sought the detection of AF ( 6 minute episode) by ILR and if detected, early start of oral anticoagulation would reduce stroke, systemic arterial embolism, cardiovascular death or all-cause death as compared to usual care. AF detection rate was higher in ILR group but initiation of oral anticoagulation therapy was not associated with larger reduction of any endpoint as compared to standard care. May be selection of patients with higher total AF burden or high BP levels will reduce outcomes in future studies.

Interesting studies were presented in the field of AF management. It appeared that pulmonary vein ablation was effective in reduction of AF recurrence in patients with persistent $A F$ and atrial fibrosis less than $20 \%$ but not in those with extensive fibrosis (DECAAF trial). This study contributes to limited current knowledge on promising role of MRI guidance for AF ablation, and we should seek also translational approaches targeting atrial fibrosis.

Patients with severely symptomatic permanent AF and narrow QRS now have also effective option of rate control therapy as CRT after atrioventricular node ablation. Use of CRT with atrioventicular node ablation in these patents (APAF-CRT trial) reduced all-cause mortality (relative risk reduction by $74 \%$ and absolute risk reduction by $27 \%$ ) as compared with optimal pharmacological rate control therapy.

More left atrial appendix closure devices are now available for stroke and embolism prevention in patients with $A F$ and contraindication for oral anticoagulant treatment (AMULET LAA trial).

Major steps have been done regarding pandemics, more vaccines are available and vaccinations are ongoing worldwide, including adolescents now, though the new mutations pose current threat. Recent studies showed that unvaccinated people have a 17 times higher risk of being admitted to hospital (6) and vaccines are effective in prevention of hospitalizations and intensive care unit admissions (7).

For us as cardiovascular specialists few reports on myocarditis and pericarditis are of particular interest. Myocarditis is reported in 1 per 100000 in young and pericarditis 1.8 per 100000 in older among 2000287 vaccinated population in US; all cases are recovered and received $2^{\text {nd }}$ vaccination dose (8). CDC reported myocarditis as 4.8 per 1000000 in younger males (9). The most recent study on myocarditis after vaccination reported 34 cases per 6.2 million population (10). So the risk with vaccination is very low and the risk of myocarditis is 6 times higher in COVID-19 infection than after vaccination (11).

Vaccine availability for all countries is urgently needed (12).

Gulmira Kudaiberdieva Editor-in-Chief

Heart, Vessels and Transplantation

Peer-review: Internal Conflict of interest: None to declare Authorship: G.K. Acknowledgement and funding: None to declare 


\section{References}

1.ESC - Online Congress Platform . Available at: URL: www.digital-congress.escardio.org.

2. McDonagh TA, Metra $M$, Adamo M, Gardner RS, Baumbach A, Bohm M, et al.; 2021 ESC Guidelines for the diagnosis and treatment of acute and chronic heart failure. Eur Heart J 2021: 0; 1-128 Doi:10.1093/eurheartj/ehab368

3. Glikson M, Nielsen JC, Kronborg MB, Michowitz $\mathrm{Y}$, Auricchio A, Barbash IM, et al.; ESC Scientific Document Group. 2021 ESC Guidelines on cardiac pacing and cardiac resynchronization therapy. Eur Heart J 2021: Doi:10.1093/eurheartj/ehab364

4. Vahanian A, Beyersdorf F, Praz F, Milojevic M, Baldus S, Bauersachs J, et al. 2021 ESC/EACTSguidelines for the management of valvular heart disease. Eur Heart J 2021; 0: 1-72. Doi:10.1093/eurheartj/ehab395

5. Visseren FL, Mach F, Smulders YM, Carballo D, Koskinas KC, Back M, et al. 2021 ESC guidelines on cardiovascular disease prevention in clinical practice. Eur Heart J 2021; 0: 1-111. Doi:10.1093/eurheartj/ehab484

6. Havers F, Pham H, Taylor CA, Whitaker M, Patel K, Anglin $O$, et al. COVID-19 associated hospitalizationsamong vaccinated and unvaccinated adults $>18$ years-COVID-NET, 13 states January 1- July 24, 2021. BMJ Yale 2021; doi: 10.1101/2021.08.27.21262356
7.Thompson MG, Stenehjem E, Grannis S, Ball SW, Naleway AL, Ong TC, et al. Effectiveness of COVID-19 vaccines in ambulatory and inpatients care settings. New Engl J Med 2021; doi: 10.1056/NEJMoa2110362

8. Diaz GA, Parsons GT, Gering SK. Myocarditis and pericarditis after vaccination for COVID-19. JAMA 2021, published August 4, $2021 . \quad$ Doi: 10.1001/jama.2021.13443

9. Wallace $M$, Oliver S. COVID-19 mRNA vaccines in adolescents and young adults: benefit-risk discussion. Published June 23, 2021. Available at: URL: www.cdc.gov/vaccines/acip/meetings/downloads/slide s-2021-06/05-COVID-Wallace-508.pdf

10. Klein NP, Lewis N, Goddard K. Surveillance for adverse events after COVID-19 mRNA vaccination. JAMA 201; doi: 10.1001/jama.2021.15072

11.Singer ME, Taub IB, KAelber DC. Risk of myocarditis from COVID-19 infection in people under age 20: A population-based analysis. BMJ 2021; doi: 10.1101/2021.0723.21260998

12. Letter: World leaders urged to boost Vaccine availability. Financial time 2021. Available at: URL: www.ft.com 